\title{
The most Effective Speaking Classroom Activities at University of Constantine
}

\begin{abstract}
:
Speaking is one of the language skills to be developed in learning foreign languages. It is defined as the delivery of language via sounds and words and it is the key of oral communication. The literature has often cited difficulties in learning how to speak a foreign language fluently and accurately. Learning how to communicate needs intensive practice which is considered the main obstacle for learners since it requires appropriate conditions such as very small groups of students and enough time which is not the case at university of Constantine. Since adding extra hours for this module and decreasing the number of students per group seem to be beyond the realm of possibility, searching for new ways to improve communication is the right solution. The purpose of this paper then is to provide both teachers and learners of English with the most effective activities which can work with the prevailing conditions that are likely to enhance learners' proficiency in speaking.
\end{abstract}

\author{
HADEF Rima \\ Faculty of Letters and Languages \\ Department of Foreign Languages \\ University of Mentouri \\ Constantine
}

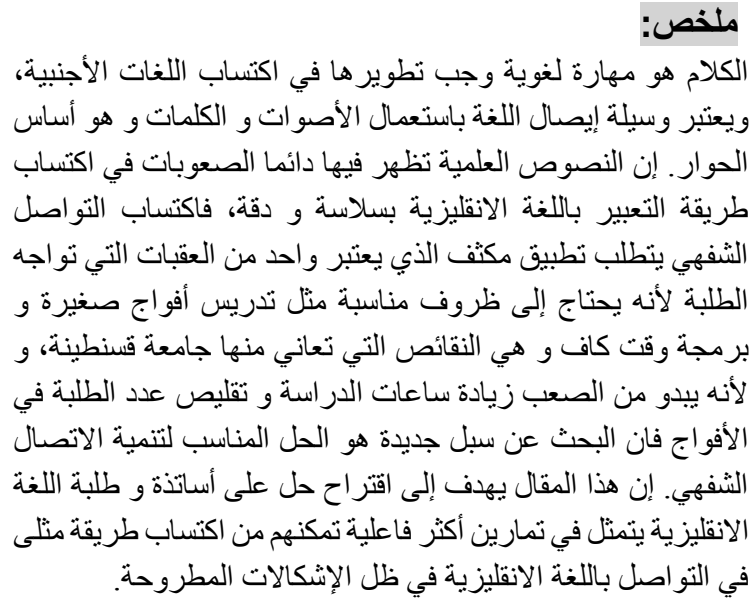

\section{Introduction:}

Improving speaking in another language that is different from the mother tongue is not without difficulty. Learners should master many features which cannot be enhanced instantaneously and automatically with the first attempt to use the target language; students need to learn the language and practise it intensively. Exhaustive practice is realized by the use of appropriate classroom activities. 
Nevertheless, getting learners practise inside the classroom is the most exigent issue in oral expression classrooms since one group contains numerous learners with different characters, introvert and extrovert, should practise the foreign language in limited time (three hours per week divided between speaking and listening). In addition, not all speaking activities are effective; some classroom speaking activities can be efficient if they are applied in small groups for a limited period of time but not with large groups for instance. This article is an attempt to scrutinize the most valuable tasks that require large amount of practice to develop speaking.

\section{Overview of the Status of Speaking in Foreign language Research and Pedagogy}

Speaking is the form of language that occurred initially in human societies. However, through the history of language research and pedagogy, the focus was more on teaching and learning the written form of language. The Grammar Translation Method, for example, based its teaching and learning techniques on writing because the "Written language was easy to observe and to codify, and the codifications themselves, in grammars and dictionaries, being written, took on a life of their own and acquired the status of 'correct' benchmarks to which any question or dispute about usage could be referred" (MacCarthy, 1998, P. 16). In other words, writing is based on specific scripted rules which can be seen and referred to.

MacCarthy (1998, P. 16) points out that although history of language research and pedagogy was based on the written form of language, the spoken one was not totally ignored. Many examples are displayed to prove this situation. The first example is about 'Vulgaria', the textbooks in Tudor times that were used at grammar schools to teach Latin (MacCarthy, 1998, P. 16). These textbooks were concerned with the spoken language by giving colloquial utterances as examples in Latin and their translation in English, such as ' $I$ was beten this morning (i.e. beaten by the scholar master), and Thou stynkest (you stink)' (White, 1932 in MacCarthy, 1998, P. 16). Despite the fact that these expressions were given in written forms, they were mostly used in speaking. In the sixteenth century, in Britain, manuals that help improve pronunciation and enunciation started to be spread. In the seventeenth and the eighteenth centuries, researchers sought to get learners pronounce the language well by making an affinity between pronunciation and orthography. In other words, they put symbols to spoken words to help pronounce them well by referring to these written symbols. The last example dates back to the nineteenth century. In that period, a kind of manual that described the spoken languages of many communities which had new contacts with Europeans was overspread.

It was not until the $19^{\text {th }}$ century that speaking came to its current focus although all examples that are mentioned above indicate that speaking was not thoroughly ignored in the history of language research and pedagogy before the 
sixties. In the $19^{\text {th }}$ century, the Reform Movement made a revolution on the Grammar Translation Methods which limited the speaking activities to the translation of first and second languages sentences and texts and memorizing lists of vocabulary. The Reform Movement argued that these kinds of activities did not help foreign language learners improve fluency in speaking (Bygate, 2009, P. 402- 403). This revolution against foreign language approaches encouraged the growing of other approaches that took speaking as their baseline. The Direct Method, the Audiolingual Method and the Audio-visual Method were some of the methods which worked on the development of the speaking skill.

Most of those new methods were developed to teach the spoken language, but they had some problems in dealing with this demanding skill. They based their teaching and learning processes on a systematic attention to pronunciation and not on interaction and communication. In the $1970 \mathrm{~s}$, researchers noticed that foreign language learners faced great problems when it came to use the language appropriately outside the classroom even if they produced it accurately. Provided that learning how to speak the foreign language correctly did not allow learners to communicate perfectly, reformers like Widdowson suggested that learners need to go beyond mastering the language system to be able to use the language for real purposes (Larsen-Freeman, 2000, P. 121). A new approach grew out to make learners reach their goals of using the foreign language for interactive and communicative purposes. This approach is called The Communicative Approach. The essential characteristics of this approach are summarized by Richards and Rogers (1986) in the following points:

1-Language is a system for the expression of meaning.

2-The primary function of language is for interaction and communication.

3 -The structure of language reflects its functional and communicative uses.

4-The primary units of language are not merely its grammatical and structural features, but categories of functional and communicative meaning as exemplified in discourse. (P. 71)

In short, the Communicative Approach views language as more than just linguistic forms; it consists of meanings and functions. It makes foreign language learners aware of many aspects of speaking like paralinguistic features and how to use the language in real contexts.

\section{Classroom Speaking Activities}

In the realm of second and foreign language acquisition, various activities are designed to teach/learn a range of skills. Each of these activities is used to improve one or more features of a skill. In oral expression classes, two types of tasks are developed: controlled and less controlled tasks.

The controlled activities are those activities which, according to Lindsay and Knight (2006) "concentrate on getting learners to produce sounds, phrases or grammatical structures... controlled activities generally focus on the learners producing language accurately" (P. 61). Nonetheless, Rivers (1971, P. 162, 163) 
pigeonholes this kind of activities as The Forging of the Instrument Activity and defines it as an activity that "requires much practice in the arbitrary associations of the new language: lexical items, morphological and syntactical patterns, sentence types". Therefore, the fundamental goal of controlled activities is the mastery of the mechanical aspects of language by practicing it until it will be a part of their speaking abilities and can be used automatically in an easy way.

Controlled activities then are based on repetition. They appeared with the development of the Audiolingual Method. In that time, repetition was used to develop language structures (Lindsay \& knight, 2006, P. 18) i.e. it was primarily used to enhance accuracy. Recently, however, repetition is used to develop another feature of the spoken language that is apparently different from grammar and pronunciation which is fluency. Even if it does not seem to be an effective task to develop fluency due to its nature as learners do nothing except imitating what others-- the teacher or native speakers from an audio tape -- are saying, undeniably, it is not. Purainen-Marsh, Alanen and Finland (2012, P. 2825) claim that repetition in language learning is not just a mechanical imitation of utterances. It is recently said that repetition-based activity aids learners speak fluently although it is a controlled task. The most important question that should be asked, however, is how it enables learners developing speaking naturally and at the same time limits their ideas and words. Duff (2000) answers this question by saying that:

the benefits of repetition is viewed as a way of providing learners greater access to language form--for example, by repeating forms for learners ...- and as a means of enabling learners to develop automaticity in the target language as they proceed from highly controlled language use to more automatic or spontaneous production of internalized forms. (P. 92)

In other words, when learners repeat an utterance or set of utterances, they acquire two main elements, language system and smoothness. At the beginning of the process, the focus is shown more on forms and by time it moves to automaticity. At first, learners find it difficult to repeat exactly what has been heard by using the same intonation, rhythm and flow of speech; learners' speech starts with lengthy pauses and lot of hesitations. Nevertheless, frequent repetition helps them learn by heart and then reiterate the passages easily with minimum pauses and hesitations.

Drills are among the oldest activities that are based on repetition. Spratt (1991, P. 210) defines them as "A type of highly controlled oral practice in which the students respond to a given cue. The response to a given cue varies according to the type of drill". Therefore, it is a form-based activity that is used at the early stage of learning a foreign language when learners do not have much knowledge of the language.

In contrast to the first kind of classroom activities that is primarily based on input and repetition, less controlled activities are based on output and 
communication. Literature in the field of teaching the speaking skill admits that this type of activities is more effective than the first one. In it, learners are asked to practise the language with each other or with their teacher; they have the opportunity to choose the language (words and structures) to express their ideas and feelings without being controlled and limited.

Interaction-based activities do not just give each learner a passage to present in front of others. Swain and Suzuki (2010, P. 565) point out that "When L2 learners participate in communicative interaction; they not only scaffold one another but also engage in 'languaging"'. In other words, students should use and practise the language in many situations for specific purposes since it is not used only to inform others. It is used to negotiate meanings, to apologize, to thank, etc. This kind of classroom activities, in which learners attempt to use the language like native speakers in real life situations, helps them acquire some specific expressions (formulaic expressions) and communicative strategies (like paralinguistic features) to accomplish communication smoothly (VanPatten \& Williams, 2006, P. 207). The commonly used activities of this kind are information-gap activities, role play and simulations and free discussion.

This distinction is made to facilitate the choice of the most appropriate tasks that go with the goals of the course. If the objective is to make learners speak accurately, the teacher uses the first kind of tasks and uses the second one to boost fluency. But both types indeed are set to accomplish both objectives with difference in priority. Baker and Westrup (2003) point out that:

In a language lesson, students need to spend time on becoming more accurate. But they also need to practice to use the language fluently. The amount of time spent on each skill will be different in each learning situation... an activity which starts with emphasis on accuracy will often give students the chance to practice speaking fluently later in the lesson. (P. 7-8).

\section{Teaching and Learning the Speaking Skill at Algerian Universities}

The speaking skill consists of different aspects such as vocabulary, pronunciation, grammar and fluency that are said to be the most prevailing ones. Before the advent of Hymes' communicative competence, the mechanical aspects of the language system such as accuracy and pronunciation were the most focused ones. Nowadays, however, the focus is more on how to make learners communicate fluently, easily and smoothly. Nevertheless, both aspects are hard to be acquired since speaking development is a long and complex process in which a considerable amount of practice should be involved.

Developing these speaking features requires suitable circumstances such as very small groups of students and enough time. Nevertheless, the environment at university of Constantine is inappropriate one since the time allocated to oral expression is not enough in addition to large classes. Three hours per week divided between two skills (speaking and listening) are not enough, especially if 
the group is a large one. Overcrowded classes sheltering more than 50 learners yield inevitably to disastrous results for both teachers and learners. Three hours per week is a poor time allowance to make all learners practise the language; and if they have the opportunity to speak in classroom, they will be devoted few seconds to utter few words. This does not contribute, in any case, to improve this skill.

Since it seems to

be beyond the realm of possibility to add extra hours or even reduce the numbers of the groups, the main suggestion around which there is a common consent is the choice of specific tasks that are likely to improve speaking. In fact, all speaking-based activities are effective but they do not have the same rate of efficiency in all conditions. In spaces similar to university of Constantine, where time constraints and large groups prevail, some activities may not reach the prime objective related to developing speaking.

\section{The Most Effective Speaking Classroom Activities}

After scrutinizing both kinds of speaking classroom activities (controlled and less controlled tasks), less controlled activities are found to be the most inspiring and resourceful tasks to improve the speaking skill at university of Constantine for the following reasons:

- Giving learners the opportunity to interact in the classroom with partners who approximately have the same academic level gives them the chance to improve their language by taking turns in discussions and conversations. In this context, Chaudron (1988) points out that: the import of this concept is that in various conversational on other task-related interaction, the 'vertical discourse' -- the sequence of turns taken with conversant-- aids learners in gradually incorporating portions of sentences, lexical items, reproducing sounds, etc. in meaningful ways rather than in mechanical repetition or lengthy monologues. (P. 10).

- Communicative-based tasks play an important role in obtaining the main objectives of second and foreign language teaching and learning methods. Recently, the goals of approaches and methods are changed from form-based to message-based and from teacher-centered instruction to learner-centered instruction. These new perspectives of language teaching and learning change the way how foreign languages are approached. Scholars argue that learners will acquire the foreign language by practising the language and using it in real contexts. Furthermore, by the involvement of learners in the teaching/learning process, learners will be responsible for their acquisition since they may know their weaknesses which help find solutions.

- This kind of activity increases self-confidence which is considered among the prime steps to acquire speaking in foreign languages. If 
learners have enough confidence in themselves and their capacities, they will take risks voluntarily i.e. learners may try to speak freely even if they know that their speech is full of mistakes. Discussions, debates and conversations or interaction tasks give learners the opportunity to speak in classroom to best increase their self-confidence. Moreover, learners of the same group, more or less, have the same level and probably commit the same kind of mistakes and errors; that is why they do not take heed of their mistakes while speaking in front of others.

- Learners enjoy such kind of activities more than others. They like to have free discussions and role plays. In both activities, learners are given topics which are familiar to them; they discuss real-life problems faced in their families or their society and incarnate roles of people with whom they may have relations. These activities can help learners feel at ease, and this may be considered as a drive that motivates them to speak and express themselves.

\section{The Roles of Teachers and Learners in Less controlled Activities}

Whenever we hear the terms teaching and learning, we think that teachers and learners have different roles to play in the classroom. When we talk about teachers, we think of them as the power of the classrooms and the persons who pass on the information to learners. Whereas, when we say learners, the first thing that comes to mind is those passive students in the classroom whose main task is to receive and absorb information. But this is not always the case when it comes to the recent language teaching and learning methods and techniques since new roles are added.

The use of less controlled activities helps students learn how to speak the target language by using it in real life situations. In this kind of activities, students learn how to speak the target language by a direct contact with it since it demands more practice to be boosted up. So, learners develop their learning process independently from their teacher without passing his/her roles by. When we come across this expression 'learner-centered instruction', we may think that teachers have little role to play in the process of teaching. Nevertheless, the teacher's role is "less dominant but no less important" (Littlewood, 1981, P. 19). Moreover, giving learners more responsibilities inside the classroom does not exclude the teacher's role.

Classroom management is one of the main roles teachers play in less controlled activities. Perceptibly, this kind of tasks exists in both kinds of activities; form-based activities and those that are based on communication. Within this role, many other roles are developed named as motivator, controller and organizer.

Motivating learners is one of the most difficult responsibilities which foreign language teachers should take in oral expression sessions. It is so difficult 
because the classroom includes learners of different personalities. The role of the teacher here is to identify the most appropriate ways to treat them and the main kinds of drives that should be used to motivate them. Wright (1987, P. 53) suggests many ways to be adopted to motivate learners. The following points are the main proposed ones:

- Adopting a positive attitude towards the learners.

- Giving pupils meaningful, relevant, and interesting tasks to do.

- Involving the learners more actively in the classroom in activities that demand inter-student communication and cooperative efforts on their part.

- Introducing learners to the concept of self-appraisal and selfevaluation through reports and discussion.

The other role within the teacher's managerial role is control and discipline. Since the teacher is seen as the headmaster who owns the power in the classroom, her/his job is to control learners' discipline. According to Wright (1987, P. 56), the teacher does not control just the behaviour and the attitude of the learners but also the ways how they are taking their courses.

The organization of groups in the classroom is another role of the teacher. The teacher has the right to put the students in groups the way s/he thinks is the appropriate one either for him/her or for the nature of the activity. Sometimes, the activity needs the interaction of the whole class like in free discussion activities whereas in other activities, the work should be given in small groups like in role play and simulations.

In addition to the responsibilities that are mentioned above, in the oral expression sessions, the teacher has other new ones summarized by Harmer (2001, P. 275- 276) in three terms: prompter, participant and feedback provider. Sometimes learners face some problems in expressing themselves either in terms of words or ideas. Since the teacher is the guide who has more information than learners, her/his role is to give them pieces of advice when they get lost. In other cases the role of the teacher changes from the headmaster of the group to a learner. In interaction-based activities, the teacher likes to take a part in the discussion to be a co-communicator. This role that is totally different from the original job designated to the teacher creates a new atmosphere in the classroom which gives a positive drive to learners to participate. It plays a great role to get learners feel at ease when participating because they think that their teacher, the power of the classroom, shares her/his ideas with them. Although, sometimes the teacher takes the task of the student, it does not militate against his/her role as a feedback provider. The teacher is considered also as a monitor who has to check the development of learners' language and corrects their weaknesses and encourages their strengths. 
Recent research in English language teaching gives more attention to the roles that are played by learners. It focuses on learner-centered instruction which adds more responsibilities and roles to learners for the sake of reaching more than just improving their autonomy in the classroom and directing the activities. Learners go beyond the practical side of the teaching process and opt for the theoretical one where they can help design the course, content and activities according to their needs.

In order to develop their language, learners should be motivated. However, in some cases the nature of the activity may not help them get this motivation which may lead to less concentration that, in turn, influences the learning process negatively. However, to motivate learners, teachers should make them aware of their needs and work on how to achieve them. In doing so, new roles should be given to learners (Farrel \& Jacobs, 2010, P. 26- 27). Hedge (2000, P. 36) summarizes those new roles in four aspects:

In contributing to course design, learners can research their needs, negotiate content, and help to monitor the process of the design. In contributing to activity design, learners can explore and experiment. In developing more independent approach, learners can plan, initiate, and organize their own works. And in the classroom where participation is high and its nature flexible, learners can question, clarify, suggest, and comment.

\section{Conclusion}

It is always seen that oral expression sessions, especially at university of Constantine for the prevailing specific conditions (large groups and limited time), are not enough to improve proficiency in speaking. Learners always need extracurricular in order to speak the foreign language naturally and accurately. However, this idea could be changed by searching for new solutions like selecting the most effective classroom activities which can help all learners improve the amount of practice in the classroom to become increasingly independent and confident. Oral expression teachers then need to take into consideration their actual case, they should select the task that accommodate the class time constrains and the size of the group. Less controlled activities are the speaking classroom activities which help teachers encourage their learners to speak more often by communicating with each other and with their teacher. It is not characterized just as an active way of learning but it minimizes learners' fears of speaking in front of the teacher and mates who are always seen as the source of inhibition. Less controlled activities are considered the best activities in which cooperative learning takes place. In it, the teacher is not seen as the source of authority, the person who can oblige learners to speak about some specific topics by using some specific expressions without making mistakes.

\section{References}


Baker, J. \& Westrup, H. (2003). Essential speaking skills: A handbook for English language teachers. Continuum.

Bygate, M. (2009). Teaching the spoken foreign language. In K. Knapp \& G. Antos (Eds.), Handbook of foreign language communication and learning. W DeG.

Chaudron, C. (1988). Second language classrooms: Research on teaching and learning. Cambridge University Press.

Duff, P. A. (2000). Repetition in foreign language classroom interaction. In J. K. Hall \& L. S. Verplaetse (Eds.), Second and foreign language learning through classroom interaction (109-138). Lawrence Erlbaum Associates.

Farrel, T. S. C. \& Jacobs, G. (2010). Essentials for successful English language teaching. Continuum for Successful Publishing Group.

Harmer, J. (2001). The practice of English language teaching. Pearson

Education Limited.

Hedge, T. (2000). Teaching and knowing the language classroom. Oxford: Oxford University Press.

Larsen-Freeman, D. (2000). Techniques and principles in language teaching. Oxford: Oxford University Press.

Lindsay, C. \& Knight, P. (2006). Learning and teaching English. New York: Oxford University Press.

Littlewood, W. (1981). Communicative language teaching: An introduction. Cambridge: Cambridge University Press.

McCarthy, M. (1998). Spoken language and applied linguistics. Cambridge: Cambridge University Press.

Purainen-Marsh, A., Alanen, R. \& Finland, J. (2012). Repetition and imitation opportunities for learning. In N. M. Seel (Ed.), Encyclopedia of the science of learning. Springer.

Richards, J. \& Rodgers, T. S. (1986). Approaches and methods in language teaching: A description and analysis. Cambridge: Cambridge University Press.

Rivers, W. M. (1971). Teaching foreign language skills. University of Chicago Press.

Spratt, M. (1991). The practice stage, discourse chains. In A. Matthews, M. Spratt \& L. Dangerfield (Eds.), At the chalkface: Practical techniques in language teaching. Walton-on-thames, UK: Thomas Nelson.

Swain, M. \& Suzuki, W. (2010). Interaction, output, and communicative language learning. In B. Spolsky \& F. M. Hult (Eds.), The handbook of educational linguistics (pp. 558-570). Wiley-Blackwell.

VanPatten, B. \& Williams, J. (Eds.). (2006). Theories in second language acquisition: An introduction. Lawrence Erlbaum Associates.

Wright, T. (1987). Roles of teachers and learners. Oxford University Press. 